\title{
Research on Security Assessment Index System for Operating Reserve in Large Interconnected Power Grid
}

\author{
Mingsong Liu ${ }^{1}$, Huadong Sun ${ }^{1}$, Jian He ${ }^{1}$, Hengxu Zhang ${ }^{2}$, Jun $\mathrm{Yi}^{1}$, Jian Zhang ${ }^{1}$ \\ ${ }^{1}$ China Electric Power Research Institute, Beijing, China \\ ${ }^{2}$ Shandong University, Jinan, China \\ Email: liums@epri.sgcc.com.cn
}

Received April, 2013

\begin{abstract}
Optimization and placement of spinning reserve is an important issue in power system planning and operation. Systematic way for security assessment of operating reserve needs to study. A security assessment index system for operating reserve in large interconnected power grids is presented in this paper. Firstly, classification and determination methods of operating reserve at home and abroad are investigated, and operating reserve is divided into transient state operating reserve and quasi-steady state operating reserve from the view of security assessment. Secondly, assessment indexes and optimization methods for transient state operating reserve are studied. Thirdly, optimization model, deterministic and probabilistic optimization methods for quasi-steady state operating reserve are explored. Finally, some principles for determination of operating reserve are suggested, and a security assessment index system is put forward. The proposed index system, considering both transient and quasi-steady state, both deterministic and probabilistic methods, provides a systematic way to assessment and arrangement of operating reserve.
\end{abstract}

Keywords: Security Assessment Index System; Operating Reserve; Spinning Reserve; Large Interconnected Power Grid

\section{Introduction}

Several major blackouts occurred in the world recent years, causing great economic losses and severe social influence [1-5]. Insufficient reserve capacity and improper placement of operating reserve are among several main reasons. Optimization and placement of spinning reserve is an important issue in power system planning and operation [6-10]. In China, power load grows rapidly with the development of economy, while power supply is far behind demand. Spinning reserve is often insufficient in period of peak load in many provinces, which is a great threat to security and stability of power system operation. How to arrange spinning reserve reasonably and effectively in a large interconnected power grid becomes a technical problem urgent to be solved.

The arrangement of spinning reserve in China is mainly according to a certain proportion of overall generation load [11], which is relatively rough. As regional interconnected power grids, intermittent renewable energy and power electronic devices increase, system characteristics and operation modes of power grids become more and more complicated. Higher requirements have been put forward to spinning reserve.

Much work has been done on optimization and placement of operating reserve, which is very helpful to power system planning and operation. However, systematic way for security assessment of operating reserve needs to study. A security assessment index system for operating reserve in large interconnected power grids is presented in this paper. Firstly, classification and determination methods of operating reserve at home and abroad are investigated, and operating reserve is divided into transient state operating reserve and quasi-steady state operating reserve from the view of security assessment. Secondly, assessment indexes for transient state operating reserve are studied, and optimization methods are introduced. Thirdly, optimization model, deterministic and probabilistic optimization methods for quasi-steady state operating reserve are explored. Finally, some principles for determination of operating reserve are suggested, and a security assessment index system is put forward. The proposed index system, considering transient and quasisteady state, deterministic and probabilistic methods, provide a systematic way to assessment and arrangement of operating reserve.

\section{Classification and Determination Methods of Operating Reserve}

\subsection{Classification and Determination of Operating Reserve in China}




\section{- Classification of operating reserve}

In China, according to its function, operating reserve is divided into load reserve, contingency reserve and maintenance reserve [11]. Load reserve is used to balance instantaneous load fluctuation and load forecasting errors, which should be spinning reserve. Contingency reserve, activated in a certain period after disturbance, is used to compensate large active power imbalance caused by contingencies, part of which should be put into operation automatically when system frequency decreases. Maintenance reserve meets the requirements of maintaining all generators periodically.

Spinning reserve usually consists of the following generators:

1) Generators that are already put into operation, without reaching their operating limits, including thermal power generators, hydro power generators, etc.

2) Hydro power generators that can be put into operation quickly, usually within several minutes.

\section{- Determination of operating reserve}

In China, operating reserve is arranged according to a certain proportion of maximum generation load [11]. Load reserve is $2 \%-5 \%$ of maximum generation load. Lower proportion is suitable for large systems, while higher proportion is for small systems. Contingency reserve is about $10 \%$ of maximum generation load, which should be greater than the largest generator of a system. Maintenance reserve is about $8 \%-10 \%$ of maximum generation load.

\subsection{Classification and Determination of Operating Reserve in America}

\section{- Classification of operating reserve}

In America, according to its function, operating reserve is divided into regulating reserve, contingency reserve, additional reserve for interruptible imports, and additional reserve for on-demand obligations [12]. Regulating reserve is similar to load reserve in China, and the same is contingency reserve. Additional reserve for interruptible imports and on-demand obligations should be made effective within ten minutes, which meet interruptible imports and on-demand obligations to other entities or balancing authorities.
Operating reserve consists of spinning reserve and nonspinning reserve. Spinning reserve means unloaded generation which is synchronized and ready to serve additional demand. Nonspinning reserve means that operating reserve not connected to the system but capable of serving demand within a specified time, or interruptible load that can be removed from the system in a specified time.

\section{- Determination of operating reserve}

In America, operating reserve is arranged in a deterministic way [13]. Regulating reserve is to provide sufficient regulating margin to meet NERC's control performance criteria, while contingency reserve is to meet NERC disturbance control standard, considering the most severe single contingency and a certain proportion of hydro, thermal generation load. The combined unit ramp rate of each balancing authority's on-line, unloaded generating capacity must be capable of responding within ten minutes.

\subsection{Classification and Determination of Operating Reserve in Europe}

\section{- Classification of operating reserve}

In Europe, according to its function, operating reserve is divided into primary control reserve, secondary control reserve, and tertiary control reserve, as shown in Figure 1 [13]. Primary control reserve is activated within seconds, while secondary control reserve is activated within minutes. Tertiary control reserve implies changes in generation or load on a contractual, market or regulatory basis, activated for a period of time, e.g. 15 minutes.

\section{- Determination of operating reserve}

In Europe, operating reserve is determined as follows [13]. Primary control reserve, proportionally distributed among each control area, is agreed to be $3000 \mathrm{MW}$, which is the maximum instantaneous power deviation for the UCTE synchronous area, based on operational characteristics concerning system reliability and size of loads and generation units. Secondary control reserve must be available to cover expected demand and generation fluctuations. A total tertiary control reserve must be available to cover the largest expected loss of power in the control area.

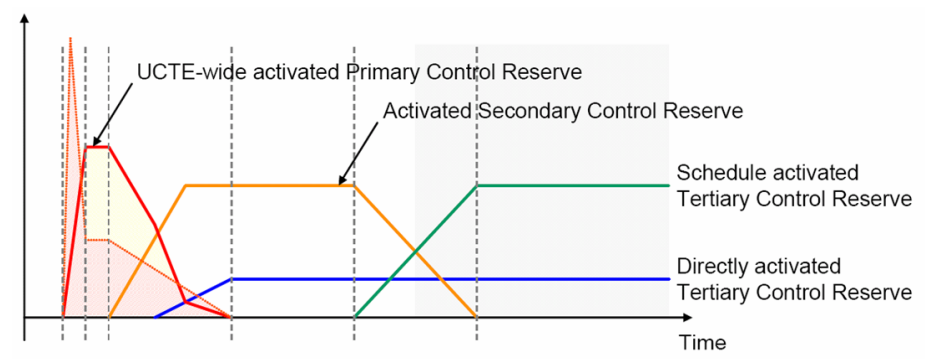

Figure 1. Principle frequency deviation and subsequent activation of reserves. 


\subsection{Classification of Operating Reserve According to Response Rate}

There are some other kinds of classification of operating reserve. In [14], reserve is divided into 10-minute spinning reserve, 10-minute nonspinning reserve, 30-minute reserve, 60-minute reserve and cold reserve. In [15], reserve is divided into instantaneous reserve, fast reserve, slow reserve and cold reserve. It is obvious that response rate is the fundamental characteristics of operating reserve. Therefore in power market, it is prone to divide operating reserve into instantaneous reserve, 10-minute spinning reserve, 10-minute nonspinning reserve, 30minute reserve, 60-minute reserve and cold reserve, as shown in Table 1.

\subsection{Classification of Operating Reserve from the View of Security Assessment}

Instantaneous reserve takes effect during transient state process immediately after a contingency, which affects system frequency deviation much. While other kinds of operating reserve take effect during quasi-steady state process, usually at least several minutes after a disturbance, which mainly affect power flow regulation.

From the view of security assessment for power system operation, operating reserve can be divided into transient state operating reserve and quasi-steady state operating reserve. Transient state operating reserve consists of instantaneous reserve, while quasi-steady state operating reserve consists of other kinds of operating reserve.

\section{Transient State Operating Reserve}

\subsection{System Frequency Response after Loss of Generation}

System frequency response after loss of generation is introduced in [16]. When a large generator trips, the disturbance spreads to each generator immediately. Due to dead zone and delay block, generator governors do not

Table 1. Classification of reserve according to response rate.

\begin{tabular}{lcc}
\hline \multicolumn{1}{c}{ Reserve } & Response Time & Synchronous \\
\hline instantaneous reserve & several seconds & Yes \\
10-minute spinning reserve & $<10 \mathrm{~min}$ & Yes \\
10-minute nonspinning reserve & $<10 \mathrm{~min}$ & No \\
30-minute reserve & $(10 \mathrm{~min}, 30 \mathrm{~min})$ & No \\
60-minute reserve & $(30 \mathrm{~min}, 60 \mathrm{~min})$ & No \\
cold reserve & $>60 \mathrm{~min}$ & No \\
\hline
\end{tabular}

take effect at once. System frequency decreases sharply. Several seconds later, governors start regulating, and active power of each generator is adjusted according to its moment of inertia and system frequency deviation. Ten or more seconds later, primary frequency control is over, but system frequency does not recover to normal value. Several minutes later, AGC takes effect, restoring system frequency to normal value.

\subsection{Assessment Index for Transient State Operating Reserve}

Dynamic characteristics of system frequency and assessment index for system frequency and spinning reserve have been studied [17-23]. There are mainly three kinds of index shown as follows.

\section{- Transient frequency deviation index}

Overall spinning reserve capacity affects system frequency response after loss of active power. On the other hand, transient frequency deviation reflects overall spinning reserve capacity. If overall spinning reserve capacity is small, transient frequency deviation becomes large. If overall spinning reserve capacity is large, transient frequency deviation becomes small.

There are several indexes for transient frequency deviation shown as follows.

1) Maximum transient frequency deviation. This index, intuitive and easy, is widely adopted in power system analysis.

2) Transient frequency deviation index using twoelement table [18]. A set of two-element tables, made up of transient frequency deviation and its duration, is used to describe transient frequency deviation acceptability for individual bus or generator.

3) Transient frequency deviation index considering cumulative effect [19]. The index, defined by integration of frequency deviation and its duration, is used to quantitatively assess transient frequency deviation security by taking into account the frequency deviation cumulative effect.

- Transient frequency time-space distribution index

After a disturbance causing large active power imbalance, transient frequency presents time-space distribution features. Since network structure, load level, generation capacity, spinning reserve capacity, dynamic model parameters are different among areas, transient frequency deviation may be different at different locations.

Some transient frequency time-space distribution indexes are used in [21], shown as follows.

1) Mean changing rate of frequency. Shortly after a disturbance, the frequency response curve is usually linear. The index reflects type and severity of the disturbance and information of network and generators. 
2) Maximum transient frequency deviation at different locations. The index is used to assess influence degree on different locations by the disturbance.

3) Transient frequency response delay at different locations. This index reflects frequency spreading process.

- Response rate of generators in primary frequency control

After a large disturbance of active power, different generators may response in different rates. Generators of different types, years and capacity have different response rate. Generally speaking, thermal generators of new type, with large capacity response fast. The faster the generators with reserve capacity response, the less the maximum transient frequency deviation is, and the shorter the duration to maximum deviation is. Response rates of generators in primary frequency control are related to difference coefficients and dead blocks of their governors [17, 24].

\subsection{Optimization of Transient State Operating Reserve}

In [22], an optimization method for spinning reserve, considering transient frequency security, is proposed. The algorithm is separated into two steps. Critical spinning reserve capacity is calculated based on sensitivity analysis. Then critical spinning reserve capacity is put into optimization model as a constraint, and the model is solved using priority list method.

In [23], an optimization method in which the transient

frequency deviation of power system is taken into account is proposed. The maximum active power of each generation unit that is allowed to undertake during primary frequency regulation is calculated. Then both spinning reserve cost and moment of inertia of each generation are comprehensively considered to give the optimization configuration scheme of spinning reserve.

\section{Quasi-Steady State Operating Reserve}

\subsection{Optimization Model of Quasi-steady State Operating Reserve}

When quasi-steady state operating reserve takes effect, a system is usually in a quasi-steady state. Transient state process can be ignored, and it becomes a problem of power flow. Optimization of quasi-steady state operating reserve is a problem of optimal power flow with several constraints, as shown in (1).

$$
\begin{aligned}
& \min F(X) \\
& \text { s.t. } \quad G(X)=0
\end{aligned}
$$

The objective function $F(X)$ represents network loss, generation cost, reserve procurement cost, social cost, or some other kinds of cost. The objective is to minimize given kind of cost.

The equality constraint $G(X)=0$ represents power flow equations.

The inequality constraint $A X \leq B$ represents a set of constraints, shown as follows.

1) Constraints of generator operation limits.

2) Constraints of generator reserve capacity.

3) Constraints of generator ramp rates.

4) Constraints of line current limits.

5) Constrains of section transfer capability.

6) Constrains of overall reserve capacity.

7) Constrains of area reserve capacity limits.

8) Constrains of system stability.

These inequality constraints can be used as security assessment indexes for quasi-state operating reserve.

\subsection{Deterministic Optimization Methods}

In traditional power industry, generation, transmission and distribution belong to one power company. Reserve capacity is provided and used by the same company. Therefore economic affairs are easy to be coordinated within the company. Power supply reliability and system operation security are the most important issues. Spinning reserve capacity is usually determined according to a certain proportion of maximum generation load, or the largest generator of a system. These methods are easy and widely used. However, they are not economically optimal.

Some optimization methods are studied to minimize reserve capacity, reserve procurement cost, etc. In [25], optimal reserve model of interconnected regional power systems is built up. The adaptive immune genetic algorithm is used to calculate the optimal reserve capacity, taking into account offset frequency, load fluctuation and security reliability constraints of the regional inter- connected power system. In [26], two approaches are adopted, the independent modeling of multi-step optimization and unified modeling of joint optimization for daily spinning reserve and generation scheduling. Different energysaving generation dispatching models are established.

\subsection{Probabilistic Optimization Methods}

Power supply reliability is a most important issue for both traditional power industry and power markets. Security and adequacy are two aspects of reliability. Probabilistic indexes, such as loss of load probability and value of lost load, are often used to evaluate system reliability.

Much has been done on probabilistic optimization methods of spinning reserve. In [27], a stochastic variable called spinning reserve's gain or loss is defined, to 
analyze the risks of spinning reserve scheme from the prospective of power generating system. A utility expectation decision-making model is proposed, reflecting both the objective risk of a spinning reserve scheme and the decision-maker's attitude to risks. In [28], a method and standards of shareable operational reserve reliability evaluation for multi-area power networks are proposed. Such random factors as the constraints of tielines, the status of on-line generations, loss of network elements, load fluctuations are considered. The reliability of each area and the whole power system are evaluated separately. In [29], an extended state-space partitioning based method to assess operating reserve of power grid connected with large-scale wind farm is proposed. Multi-state model of wind turbine generator is adopted, and the total state space, divided into two subspaces, can be chosen by state enumeration method and Monte Carlo simulation respectively. In [30], a mathematical model for deploying distributed generation as reserve is built up. Loss of load probability is used to evaluate the reliability of power supply, and different optimal deployment scheme for distributed generators are given under different reliability targets.

\section{Security Assessment Index System for Operating Reserve}

\subsection{Some Principles for Operating Reserve}

Requirements of operating reserve capacity are closely related to system scale, network structure, characteristics of load and generation, etc. It is better to make systematic assessment for a power grid before arranging its reserve capacity, instead of using a certain proportion roughly.

When a DC line with large active power is connected to a power grid, severe impacts on the grid may be caused if an outage occurs in one pole of the DC line. Spinning reserve capacity needs improving, according to frequency response characteristics after the outage.

When large amount of wind power is connected to a power grid, wind power, with characteristics of fluctuation and intermittence, requires even higher spinning reserve capacity. Spinning reserve capacity needs improving, and the spinning reserve for wind power should be close to wind power.

Transient frequency deviation is close related to active power disturbance. For a power grid, the active power disturbance should be maximum active power imbalance considering N-1 contingencies. However, if control measures are designed for a contingency, it should be analyzed separately.

\subsection{Recommended Security Assessment Index System}

A recommended security assessment index system for operating reserve in large interconnected power grid is shown in Table 2.

For transient state operating reserve, deterministic assessment methods are mainly adopted. Transient frequency deviation indexes, such as maximum transient frequency deviation, index using two-element table and index considering cumulative effect, are used to assess overall spinning reserve capacity. Transient frequency time-space distribution indexes, such as mean changing rate of frequency, maximum transient frequency deviation and transient frequency response delay at different locations, are used to assess spinning reserve distribution characteristics. Response rate of generators in primary frequency control is used to assess spinning reserve response.

For quasi-steady state operating reserve, both deterministic and probabilistic methods are adopted. Indexes such as available transfer capability and generator ramp rates are used to assess security of operating reserve. Indexes such as loss of load probability and value of lost load are used to assess operating risk considering operating reserve.

\section{Conclusions}

Optimization and placement of spinning reserve is an important issue in power system planning and operation. Classification and determination methods of operating reserve at home and abroad are investigated at first, and a new classification of operating reserve from the view of security assessment is presented. Then assessment indexes and optimization methods for both transient state and quasi-steady state operating reserve are studied. At last a security assessment index system for operating reserve in large interconnected power grids is put forward. The proposed index system takes into account

Table 2. Recommended security assessment index system.

\begin{tabular}{|c|c|c|c|}
\hline Reserve Type & $\begin{array}{l}\text { Assessment } \\
\text { Methods }\end{array}$ & $\begin{array}{l}\text { Assessment } \\
\text { Object }\end{array}$ & $\begin{array}{l}\text { Assessment } \\
\text { Indexes }\end{array}$ \\
\hline \multirow{3}{*}{$\begin{array}{l}\text { Transient } \\
\text { state } \\
\text { operating } \\
\text { reserve }\end{array}$} & \multirow{3}{*}{ Deterministic } & Capacity & $\begin{array}{l}\text { Transient frequency } \\
\text { deviation index }\end{array}$ \\
\hline & & Distribution & $\begin{array}{l}\text { Transient frequency } \\
\text { time-space distribution } \\
\text { index }\end{array}$ \\
\hline & & Response & $\begin{array}{l}\text { Response rate of } \\
\text { generators in primary } \\
\text { frequency control }\end{array}$ \\
\hline \multirow{2}{*}{$\begin{array}{l}\text { Quasi-steady } \\
\text { state } \\
\text { operating } \\
\text { reserve }\end{array}$} & Deterministic & Security & $\begin{array}{l}\text { Available transfer } \\
\text { capability, generator } \\
\text { ramp rates, etc. }\end{array}$ \\
\hline & Probabilistic & $\begin{array}{l}\text { Operating } \\
\text { risk }\end{array}$ & $\begin{array}{l}\text { loss of load probability, } \\
\text { value of lost load, etc. }\end{array}$ \\
\hline
\end{tabular}


transient and quasi-steady state, deterministic and probabilistic methods, and provides a systematic way to assessment and arrangement of operating reserve.

\section{REFERENCES}

[1] Y. Xue and S. Xiao, "Comprehensively Defending High Risk Events with Low Probability," Automation of Electric Power Systems, Vol. 35, No. 8, 2011, pp. 1-11.

[2] G. Andersson, P. Donalek, R. Farmer, et al., "Causes of the 2003 Major Grid Blackouts in North America and Europe, and Recommended Means to Improve System Dynamic Performance," IEEE Transactions on Power Systems, Vol. 20, No.4, 2005, pp. 1922-1928. doi:10.1109/TPWRS.2005.857942

[3] Y. Tang, G. Bu and J. Yi, "Analysis and Lessons of the Blackout in Idian Power Grid on July 30 and 31, 2012," Proceedings of the Chinese Society for Electrical Engineering, Vol. 32, No. 25, 2012, pp. 167-174.

[4] W. Lin, Y. Tang, H. Sun, et al., "Blackout in Brazil Power Grid on February 4, 2011 and Inspirations for Stable Operation of Power Grid," Automation of Electric Power Systems, Vol. 35, No. 9, 2011, pp. 1-5.

[5] Y. Fang, "Lessons from September 8, 2011 Southwest America Blackout for Prevention and Control of Cascading Outages," Automation of Electric Power Systems, Vol. 36, No. 15, 2012, pp. 1-7.

[6] X. Shu, Z. Ming, L. Gengyin, et al., "On Spinning Reserve Determination and Power Generation Dispatch Optimization for Wind Power Integration Systems," in Power and Energy Society General Meeting, 2012, pp. 1-7.

[7] M. Q. Wang, H. B. Gooi and S. X. Chen, "Optimising Probabilistic Spinning Reserve using an Analytical Expected-energy-not-supplied Formulation,” Generation, Transmission \& Distribution, IET, Vol. 5, No.7, 2011, pp. 772-780. doi:10.1049/iet-gtd.2010.0805

[8] A. Hoballah and I. Erlich, "Dynamic Stability and NetWork Constrained Optimal Spinning Reserve Allocation,” in Power and Energy Society General Meeting, 2011, pp. 1-5.

[9] C. Wang, Y. Qiao and Z. Lu, “A Method for Determination of Spinning Reserve in Wind-thermal Power Systems Considering Wind Power Benefits," Automation of Electric Power Systems, Vol. 36, No. 4, 2012, pp. 16-21.

[10] G. Zhao, T. Liu and X. Li, "Optimal Deployment of Distributed Generation as Backup Generators,” Automation of Electric Power Systems, Vol. 33, No. 1, 2009,pp. 85-89.

[11] “Guide on Security and Stability for Power System,” DL 755-2001, Beijing: China Electric Power Press, 2001.

[12] NERC, “Operating Reserves,” WECC Standard BAL-STD-002-0, 2007. http://www.nerc.com/page.php?cid=2|20

[13] ENTSO-E, "Load-Frequency Control and Performance [C],” UCTE OH - Policy 1, 2009.

https://www.entsoe.eu/publications/system-operations-r eports/operation-handbook/

[14] J. Wang, "Study on Reserve Capacity in Power Market," Ph.D. Thesis, Xian Jiaotong University, Xian, 2003.

[15] Y. Lai, Y. Xue, D. Wang, et a1., "Risk Decision-marking for Reserve Capacity Market," Automation of Electric Power Systems, Vol. 30, No. 16, 2006, pp. $1-5$.

[16] B. Cai, "Power System Frequency,” Beijing: China Electric Power Press, 1998.

[17] H. Zhou, L. Ni and T. Xu, "Study on Power-Frequency Dynamic Characteristic of Power Grid," Power System Technology, Vol. 33, No. 16, 2009, pp. 58-62.

[18] T. Xu and Y. Xue, "Quantitative Assessments of Transient Frequency Deviation Acceptability," Automation of Electric Power Systems, Vol. 26, No. 19, 2002, pp. 7-10.

[19] H. Zhang, Y. Liu and Y. Xue, "Quantitative Assessment of Transient Frequency Deviation Security Considering Cumulative Effect," Automation of Electric Power Systems, Vol. 34, No.24, 2010, pp. 24.

[20] H. Zhang, and Y. Liu, "Disturbance Identification Considering Differences in Frequency Deviation Propagation Speed," Automation of Electric Power Systems, Vol. 34, No. 22, 2010, pp. 62-66.

[21] Z. Hou, "Dynamic Characteristic Analysis of Power System Frequency," Master Thesis, Shandong University, Jinan, 2012.

[22] M. Liu, J. He, H. Zhang, et al., "Study on Optimization and Implementation of Spinning Reserve in Large Interconnecting power grid," China Electric Power Research Institute, 2011.

[23] M. Liu, H. Sun and J. He, “An Optimization Method for Spinning Reserve in Primary Frequency Control Considering Transient Frequency Deviation,” Power System Technology, Vol. 35, No. 8, 2011, pp. 129-133.

[24] Q. Zhao, L. Wang, Z. Liu, et al., "Study on Dynamic Frequency Characteristics and Coordinative Under-Frequency Load Shedding Scheme for Nationwide Interconnected Power Grid of China,” Power System Technology, Vol. 33, No. 8, 2009, pp. 35-40.

[25] J. Wu, M. Shi, G. Chen, et al., "Immune Genetic Algorithms for Modeling Optimal Reserve Capacity of Interconnected Regional Power Systems,” Proceedings of the CSEE, Vol. 29, No. 1, pp. 14-20, 2009.

[26] G. Xie, L. Zhang and J. Ge, "Optimization of Spinning Reserve Scheduling of Energy-saving Generation Dispatching," Automation of Electric Power Systems, Vol. 33, No. 13, 2009, pp. 43-46.

[27] X. Qi and M. Ding, "Risk Analysis and Utility Decision-making of Spinning Reserve Scheme in Power Generating System," Automation of Electric Power Systems, Vol. 32, No. 3, 2008, pp. 9-13.

[28] Y. Jia, Z. Yan, Y. Sun, et al., "Shareable Operational Reserve Reliability Evaluation for Multi-area Power Networks," Automation of Electric Power Systems, Vol. 33, No. 16, 2009, pp. 13-18.

[29] J. He, H. Sun and M. Liu, "Extended State-Space Parti- 
tioning Based Operating Reserve Risk Assessment for Power Grid Connected With Wind Farms,” Vol. 36, No. 3, 2012, pp. 257-263.

[30] G. Zhao, T. Liu and X. Li, “Optimal Deployment of
Distributed Generation as Backup Generators,” Automation of Electric Power Systems, Vol. 33, No. 1, 2009, pp. 85-89. 